\title{
FROM SFM TO 3D PRINT: AUTOMATED WORKFLOW ADDRESSED TO PRACTITIONER AIMED AT THE CONSERVATION AND RESTAURATION
}

\author{
L. Inzerillo ${ }^{\text {a*}, \text { F. Di Paola }}{ }^{\text {a }}$ \\ ${ }^{a}$ DARCH, Department of Architecture, Polytechnic School, 90128 Palermo, Italy - \\ laura.inzerillo@unipa.it, francescco.dipaola@unipa.it
}

KEY WORDS: SfM, Image Based Modeling, Automation, Restauration, Conservation, 3D printing

\begin{abstract}
:
In In the last years there has been an increasing use of digital techniques for conservation and restoration purposes. Among these, a very dominant rule is played by the use of digital photogrammetry packages (Agisoft Photoscan, 3D Zephir) which allow to obtain in few steps 3D textured models of real objects. Combined with digital documentation technologies digital fabrication technologies can be employed in a variety of ways to assist in heritage documentation, conservation and dissemination.

This paper will give to practitioners an overview on the state of the art available technologies and a feasible workflow for optimizing point cloud and polygon mesh datasets for the purpose of fabrication using 3D printing. The goal is to give an important contribute to confer an automation aspect at the whole processing. We tried to individuate a workflow that should be applicable to several types of cases apart from small precautions. In our experimentation we used a DELTA WASP 2040 printer with PLA easyfil.
\end{abstract}

\section{INTRODUCTION}

Digital manufacturing techniques or 3D printing allow us, by numerical control machines (CNC), to create physical objects directly from 3D digital geometries bypassing the production and interpretation of technical drawings. Until today, the latter represented the only communication tool between two phases: design and production; which have always been distinct and never really integrated into one process.

Thanks to the development of new technologies that increase the degree of accuracy and reduce production costs, digital manufacturing is now successfully applied in many different contexts.

In the field of conservation, diagnosis and restoration of Cultural Heritage (CH) (Inzerillo, Dalli Cardillo 2013), several and consolidated procedures have been started by museum institutions, supervisors and specialized agencies that use computerized and automated processes to enhance their traditional research tools.

The use of 3D printing systems is now consolidated, specially, in the field of 3D artworks reproduction for exhibitions in museum itineraries or for reconstructions of missing parts, resulting from destruction or damage (Alberghina, et al. 2016; Arbace, et al. 2012).

It is known that the traditional approach of producing rubber molds for replication of plaster or resin copies requires a molding procedure on the original work, which is, in fact, an invasive operation that could cause irreversible damage.

Digital manufacturing is particularly effective and functional in terms of flexibility, reversibility and non-invasibility (Lo Presti, et al. 2011).

Indeed, when a practitioner starts to print the 3D model often incurs in unpleasant inconveniences and this is aggravated if the 3D model has been carried out from SfM techniques. This is because the SfM model is often jagged and requires more steps of geometric elaboration. The goal of this paper is to design a workflow aimed at define the whole process from the 3D SfM model to the 3D print. It is known that not all the 3D models are "printable". The requirements of 3D models are many and we will describe them in the paper. Some of them are related to the shape and detail but, some other are more basic like the triangulation, the closing, the shelling and the topologically cleaning. So, not all 3D models are directly printable but may require conversion, resampling, heavy edit. If the $3 \mathrm{D}$ model author well knows all these conditions, can easily create his model using strategies to create a printer friendly geometries. But when the practitioner carries out the 3D model by a SfM technique, there are more probabilities that it will be an unprintable model. The printer cannot directly handle a 3D model but needs clear instructions on how to print it.

The main requirements are, for example, the slice of the object depending on the dimension of the print model; or the closing of the object or the construction of a geometrical plan to support a particular shape and create the stability to the physical printed model (Neumüeller, et al. 2014).

There will always be unprintable models and unprintable geometries! Particular attention is needed when there are overhang or outstanding parts or steeps surfaces or undercuts. Beyond that it is necessary to familiarize yourself with the 3D machine temperature both of the wire and of the plant. The plastic shrinks when cooling, curling or cracking the object. It should be happened that during the printing the are some thickening of the plastic material and this compromises the whole process. Sometimes, the inexpensive printers are more efficient than the sophisticated ones that requires more training and experience. Obviously there are to consider some different material: ceramic, metal and sintering, hybrid and even stone (to replicate shape and material of a work art on the Cultural Heritage field) printers are available on the market. The practitioner will choose the most 
suited to his needs. At the end, but not for importance, there is to consider the maintenance (like the nozzle cleaning or some misalignment of the mechanical arms) and small repairs of a 3D printer.

Considering that nowadays, there are valid automated alternative for the SfM process, like Autodesk 3D Catch or Recap and other ones are going to be able on the web, if there is a clear methodology to go through from the SfM model to the 3D printing the practitioner is able to create a $3 \mathrm{D}$ printed model that will realize his own design ideas.

In the history of manufacturing, subtractive methods have often come first. The province of machining (generating exact shapes with high precision) was generally a subtractive affair, from filing and turning through milling and grinding.

Additive manufacturing's earliest applications have been on the toolroom end of the manufacturing spectrum. For example, rapid prototyping was one of the earliest additive variants and its mission was to reduce the lead time and cost of developing prototypes of new parts and devices, which was earlier only done with subtractive toolroom methods (typically slowly and expensively). However, as the years go by and technology continually advances, additive methods are moving ever further into the production end of manufacturing. Parts that formerly were the sole province of subtractive methods can now in some cases be made more profitably via additive ones (Mendoza, et al. 2015; Taufik, et al. 2014).

However, the real integration of the newer additive technologies into commercial production is essentially a matter of complementing subtractive methods rather than displacing them entirely. Predictions for the future of commercial manufacturing, starting from today's already- begun infancy period, are that manufacturing firms will need to be flexible, ever-improving users of all available technologies in order to remain competitive. We started our journey into 3D printing a few months ago by using a WASP 20/40, a Delta printer. We chosen a pre-assembled $3 \mathrm{D}$ printer, because assembling a 3D printer kit was certainly not easy and the learning curve was definitely steep.

Before starting with our experience and the experimentation we carried out, we report below some briefing aspect regarding the $3 \mathrm{D}$ printing.

\section{3D PRINTING}

\subsection{What to do to make the 3D printer work}

As just said before, the 3D printing works with making a virtual 3D model of the object to print. The 3D model is for instance a CAD (Computer Aided Design) file that is created using a 3D modeling application through a 3D scanner or SfM techniques. The 3D survey techniques, those image-based and range-based ones, are focused to carry out the exactly copy of an existing object. When the 3D model is carried out, is necessary to make another step of working before it is ready to be 3D printed.

You have to adjust the 3D model into hundreds or thousands of horizontal layers and needs to be done with software. This is the slicing phase.

Each 3D printer needs different source to make the slicing steps. Sometimes a 3D model can be sliced from within a 3D modeling software application. It is also possible that you are forced to use a certain slicing tool for a certain $3 \mathrm{D}$ printer. At the end of this process the model is ready to be $3 \mathrm{D}$ printed. The connection between the ready model and the printer is available through USB, SD or wifi. Sometimes the wifi connection does not have a strong signal and you need to update the 3D sliced model in the SD card. Some 3D printers do not have the USB output, but work with the wifi connection or SD card but, some other printers have the USB output but not the wifi connection. It really depends on what brand and type 3D Printer you have. When a file is uploaded in a 3D printer, the object is ready to be $3 \mathrm{D}$ printed layer by layer. The $3 \mathrm{D}$ printer reads every slice (2D image) and creates a three dimensional object.

(https://3dprinting.com/what-is-3d-printing/).

Therefore, after all this, it is clear that you need to know your 3D printer and understand how to create the 3D model. Even before you create your 3D model you must know the strengths and weaknesses of your 3Dprinter. Then, you chose the 3D acquiring technology and finally make the 3D printing. Let's take a quick look at the different types of 3Dprinting.

\subsection{Different types of 3D printing technologies}

Nowadays exist different types of 3D printing technologies. The most diffused one is the one that use the Additive Manufacturing (AM) methods. The 3D printers that work with the AM method not use the same technology. The technology changes according the way layers are built to create the final object.

The American Society for Testing and Materials (ASTM) group "ASTM F42 - Additive Manufacturing", developed a set of standards that classify the Additive Manufacturing processes into 7 categories according to Standard Terminology for Additive Manufacturing Technologies (Fig. 1). Additive Manufacturing Technologies (Gibson, et al. 2014; Excell, 2013, Kodama, 1981a).

The seven processes are classified as follow:
1. Vat Photopolymerisation
a. Stereolithography (SLA)
b. Digital Light Processing (DLP)
c. Continuous Liquid Interface
2. Material Jetting
3. Binder Jetting
4. Material Extrusion
a. Fused Deposition Modeling (FDM)
b. Fused Filament Fabrication (FFF)
5. Powder Bed Fusion
a. Selective laser sintering (SLS)
6. Sheet Lamination
7. Directed Energy Deposition

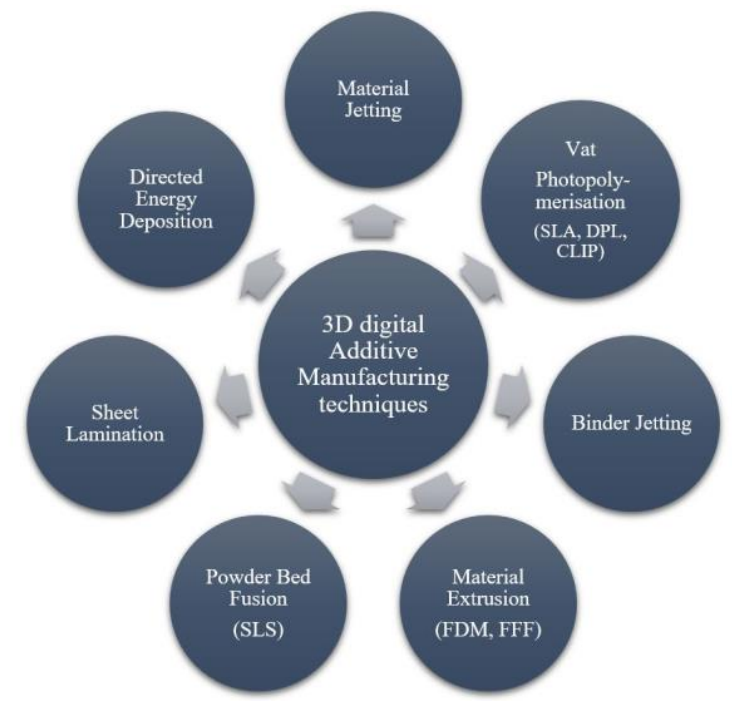

Figure 1. Different types of 3D digital Manufacturing technologies 
1) The Vat Photopolymerisation method provides to have a container filled with photopolymer resin which is then hardened with a UV light source. Within the Vat Photopolymerisation method, there are the Stereolithography (SLA), that is the most commonly used, the Digital Light Processing (DLP), that makes use of light and photosensitive polymers and the Continuous Liquid Interface Production (CLIP), that is ultrafast.

2) In Material Jetting, material is applied in droplets through a small diameter nozzle, similar to the way a common inkjet paper printer works, but it is applied layer-by-layer to a build platform making a 3D object and then hardened by UV light.

3) With Binder Jetting two materials are used: powder base material and a liquid binder. In the build chamber, powder is spread in equal layers and binder is applied through jet nozzles that "glue" the powder particles in the shape of a programmed 3D object.

4) The Material Extrusion process uses a method of rapid prototyping. Within it there are two different technology: the Fused Deposition Modeling (FDM) and the Fused Filament Fabrication (FFF). The first one is the one used by WASP DELTA 20/40 (Kodama, 1981b).

5) Powder Bed Fusion/Selective Laser Sintering (SLS) uses a high power laser to fuse small particles of plastic, metal, ceramic or glass powders into a mass that has the desired three dimensional shape.

6) Sheet Lamination involves material in sheets which is bound together with external force. Sheets can be metal, paper or a form of polymer. Metal sheets are welded together by ultrasonic welding in layers and then $\mathrm{CNC}$ milled into a proper shape.

7) Directed Energy Deposition is mostly used in the high-tech metal industry and in rapid manufacturing applications. The 3D printing apparatus is usually attached to a multi-axis robotic arm and consists of a nozzle that deposits metal powder or wire on a surface and an energy source (laser, electron beam or plasma arc) that melts it, forming a solid object.

\subsection{DELTA 3D printers}

Delta 3D printers use the FFF / FDM technologies depending on the coordinate systems and the mechanical arrangements.

Some manufacturers choose mechanical simplicity at the expense of moving the build platform while others attempt to increase extruder head speed by using fixed motors and complex belt actuation. The most popular mechanical arrangements for FFF / FDM 3D printers are:

$\begin{array}{ll}- & \text { Cartesian-XY-head } \\ - & \text { Cartesian-XZ-head } \\ - & \text { Delta } \\ - & \text { CoreXY } \\ - & \text { Polar } \\ - & \text { Scara (robot arm) }\end{array}$

As said before we used the WASP DELTA 20/40.

Delta 3D printers also work within the Cartesian plane, however the setup of the frame is totally different. They are called Delta because the extruder head is suspended by three arms in a triangular configuration. Besides that they have a circular print bed. In Delta 3D printer the moving parts are lightweight and, therefore, limit the inertia. That results is a faster printing with greater accuracy.

\section{WORKFLOW}

\subsection{FDM printing pipeline}

Once you are chosen the object to acquire you must choose the acquisition technique. In our case, for the identified case studies, we were chosen SfM technique and we processed the data set in Photoscan Agisoft (Inzerillo, et al. 2013) and carried out an .obj model to upload in the 3D printing software. (Fig. 2, 3).

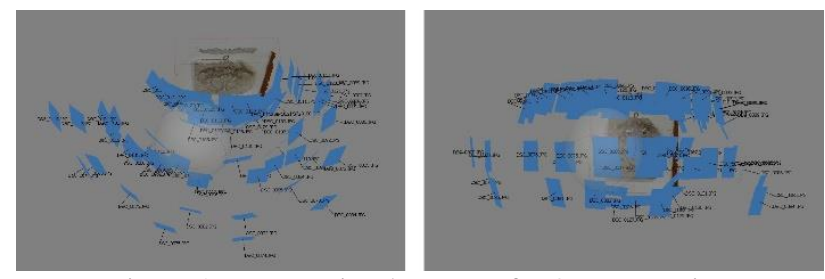

Figure 2. Data set in Photoscan for 3D processing

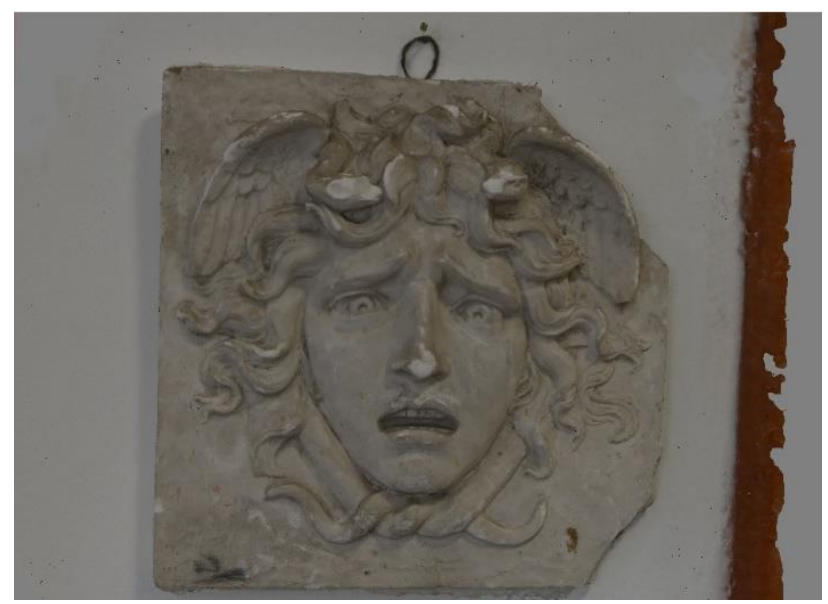

Figure 3. Textured 3D model carried out from Photoscan

Obviously, the same procedure has been adopted for the other case studies.

For the $3 \mathrm{D}$ printing, we used a rapid prototyping process (RP) with FDM additive technology. The thermoplastic polymer used for 3D printing is the polylactic acid, better known as PLA, generated by the fermentation of corn.

Digital models, obtained by a reverse engineering digital capture, require a geometry check (slicing phase) before starting the printing process.

In figure 4 is shown the standard pipeline to adopt from the slicing to the $3 \mathrm{D}$ printing phases.

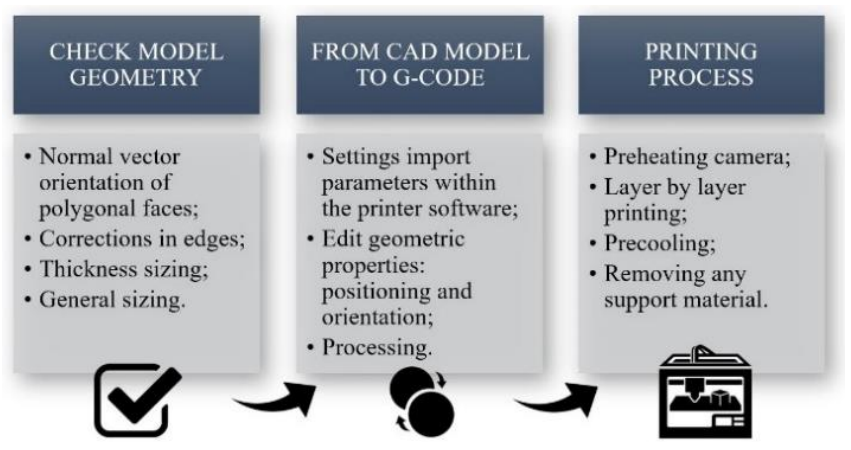

Figure 4. From check model to printing process 
The first step involves checking model geometry, investigating its polygonal mesh structure.

While creating polygon meshes, structured on spatial data in the form of point clouds, we often find out topological errors.

We list the most common among them:

- discontinuities and/or gaps in the polygon network;

- not uniform trend of normal vectors to polygonal faces;

- normal vectors facing the inside of solid volume;

- manifold edges shared by more than two polygonal faces, which determine self-intersections.

The frequent presence of these errors can result from a lack of metric-spatial information, caused by a variety of factor linked to the time of survey or to operator mistakes.

Therefore, to solve the above problems that would not allow us to proceed with printing, it is necessary to start a correction tools in post-process.

We list the most common among them:

- detection of abnormal and/or irregular faces and their correction;

- check of polygonal faces intersection and their correction;

- peaks removal;

- Seams in polygonal mesh.

In addition, depending on the material and the type of printing technology we are going to employ, we will handle dimensional limits such as minimum thickness or maximum dimensions of the object.

Completed the check and correction phase of the geometry, the object prototyping phases begin.

The second step analyzes the conversion and export process of CAD model in a format that enables communication between the CAD modeling software and the printer management ones.

Among the standard formats for 3D printing, the best known is the .stl format (Standard Triangulation Language). The export to .stl discretises the object surface in triangles and it stores the data in the form of spatial coordinates and vectors; they representing, respectively, the triangles and the normal of the polygonal faces. Other formats useful to an effective export model can be: obj; .ply; .vrml or the latest .amf.

The file can be imported and read within a Computer Aided Manufacturing (CAM) software that allows us to set the print parameters and to define critical undercut or overhanging areas, if there are.

There are many different types of preparation software to print commonly said slicer; among the open source, the best known slicing tools are: Cura (developed by UltiMaker) and RepetierHost (developed by Hot-World GmbH).

Through the operation of slicing, the plastic filament is melted and deposited on the plate in overlapping layers.

\subsection{D print workflow and parameter settings}

The 3D printer used in our laboratory is the professional, compact Italian Delta 2040 designed by WASProject that has a heated extruder mounted on a delta robot type structure, a work plan, a group of coils and a heated room that allows maximum print sizes of $200 \times 200 \times 400 \mathrm{~mm}$.

Controlled temperature ambience and amortized bowden guarantee a controlled shrink of the material and better results in the final print.

In order to test the potential of the 3D printer, we started experimenting with the reproduction of some models.

These have been appropriately chosen for different features: geometric shape, topology, dimensions, undercuts, details accuracy.

Selected models have organic and polygonal geometric shapes, characterized by: complex areas, sharp edges, meticulous details, overhanging.
These elements offer some operational and logistic critical issues to be attended during the print setup phase.

Here, we show the results applied to the following models:

a. a model representing the Greek mythological figure, Medusa;

b. a model reproducing a pothole reproduced to scale;

c. a model reproducing a medieval castle;

d. a model reproducing the Empire State Building.

The last two models are proposed by the Wasp team, and have provided a useful reference for determining an optimum set of parameters in relation to the starting characteristics.

The following describes the methodology applied to the case studies (Fig. 5, 6, 7, 8).

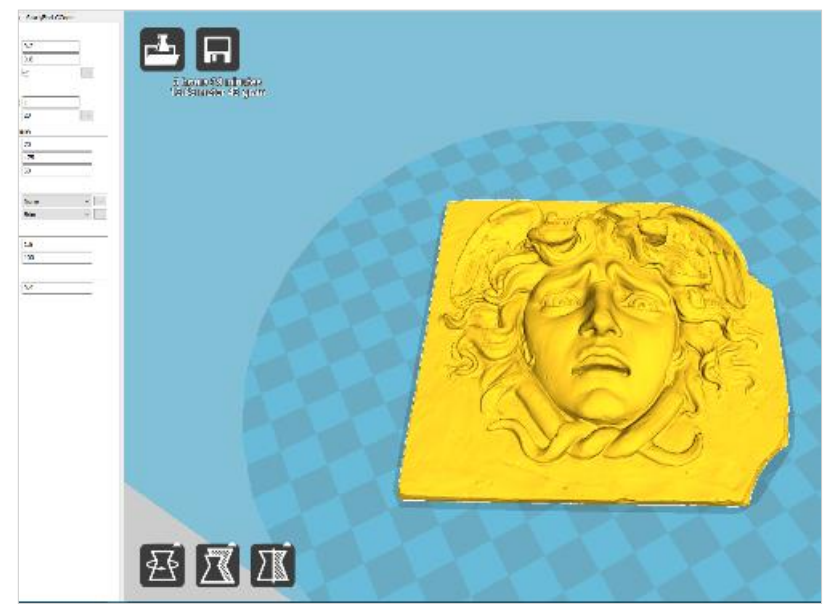

Figure 5. The main screen of Cura; the Medusa mask, horizontal position, normal view mode

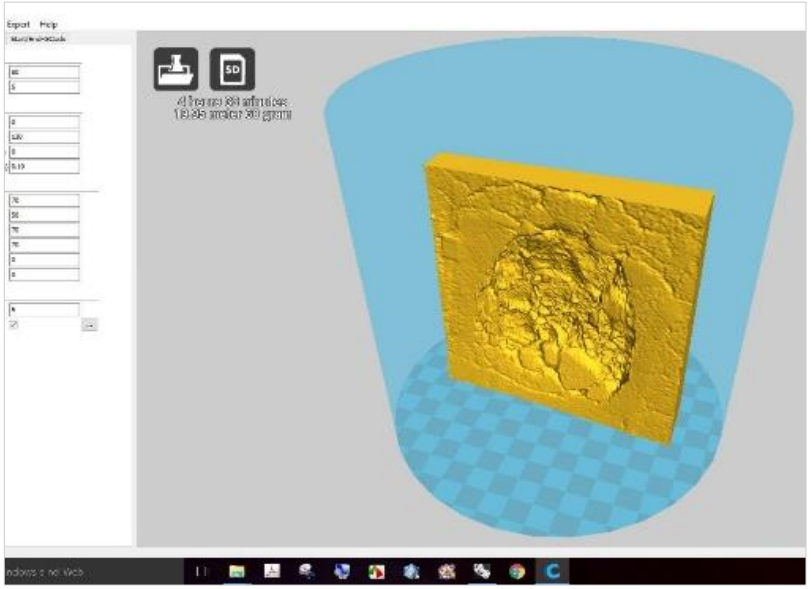

Figure 6. The main screen of Cura;

the pothole model, normal view mode

Before sending the file to the print device, we need to orient and position (rotate, scale dimensions) the object on the platform. If preferential placement couldn't be determined, the software automatically determines a position that can keep the model static equilibrium throughout the printing process

In general, in relation to the assigned configuration, some models have overhanging parts, which means that part of the model floats in the air when we would print it. In this case, we will need support to prevent the plastic from falling down. 


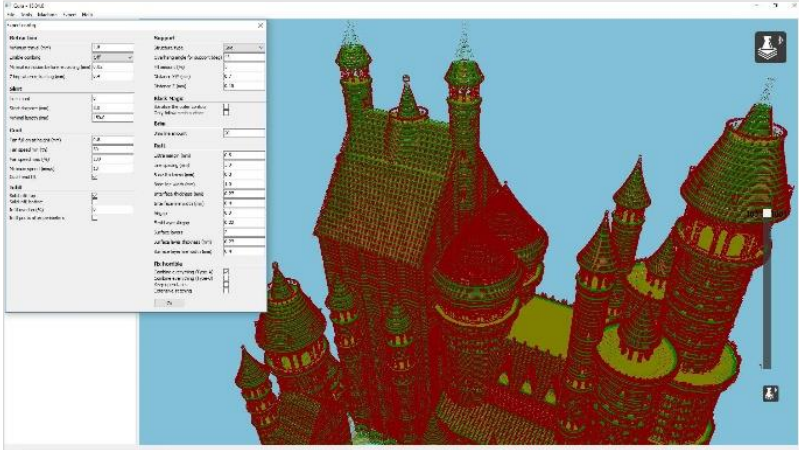

Figure 7. The expert settings screen of Cura: medieval castle model

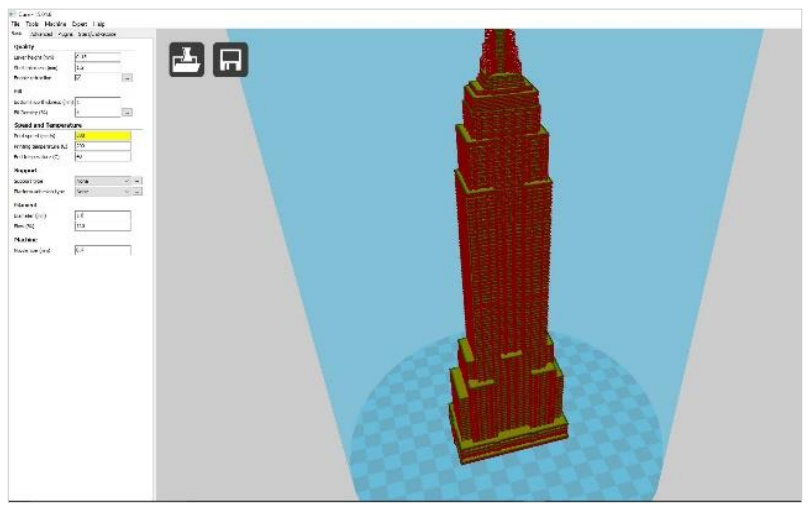

Figure 8. The main screen of Cura: Empire State Building model, layers view mode

In these areas, the software automatically provides the addition of support material to the geometric structure that can be placed on or inside a model. This material will guarantee stability during the production phase and, at the end of the process, it will be removed (Fantini, et al. 2008; Freedman, 2012).

For the mask we tried to print the model in two different positions in the space of the Cura platform, without any other changes. The choice was oriented in order to carry out a more accurate $3 \mathrm{D}$ printing. In fact, in the horizontal position the $3 \mathrm{D}$ print is not satisfying; while in the vertical position the quality is more accurate (Fig. 9).

In the next print settings step, the two parameters of greatest interest are the layer height and the material density.

They strongly influence the printing time, costs and the final quality and resolution of the object.

The layer height is the thickness (in $\mathrm{mm}$ ) of the material layers, in the $\mathrm{z}$ direction, which will be gradually deposited.

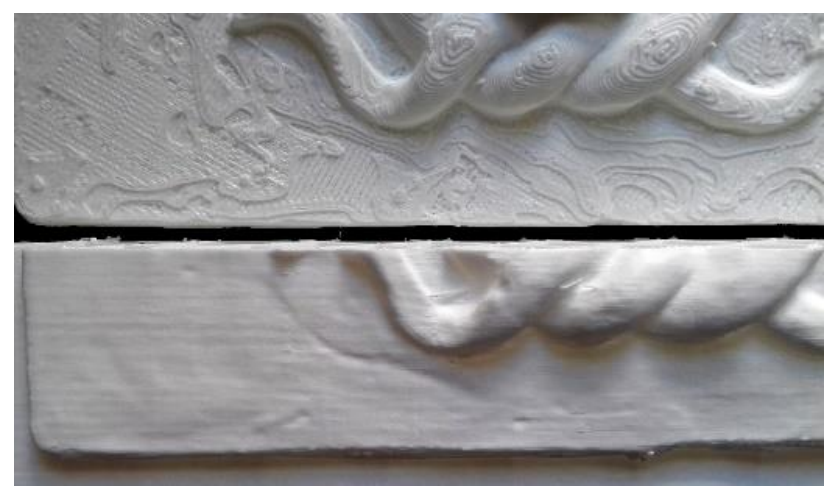

Figure 9. The Medusa mask; up side, horizontal printing; down side, vertical printing
We can of course use thinner layers to increase the quality or use thicker layers for faster prints (Fig. 10).

The material density acting, instead, on the amount of material deposited during the movement on the xy plane and it determines the porosity of the material.

These settings (fill density parameter) very much relate to the strength of the print (Fig. 11, 12, 13).

A higher fill density of course means that there's more plastic on the inside of your print, leading to a stronger object.

We can also decide to print the object completely hollow, which is desired in some cases.

At this point, the processing starts cutting the model in a series of layers (slicing operation) and it defines the parts in which the application of the support material will be required.

The process translates in a G-Code file that lists an orderly sequence of codes, spatial coordinates, and commands in programming language (the following parameters are included in the Gcode: nozzle temperature, bed temperature, material flow, fan speed, filament diameter, etc.) (Menna, et al. 2016).

The extruder of the $\mathrm{CNC}$ machine will execute these instructions during the $3 \mathrm{D}$ printing process.

After the G-Code processing phase, it is possible to transmit the information to the printing machine. In order to avoid shrinkage or deformation of the plastic material, prior to depositing the material, the chamber is heated in advance, for about 30 minutes.

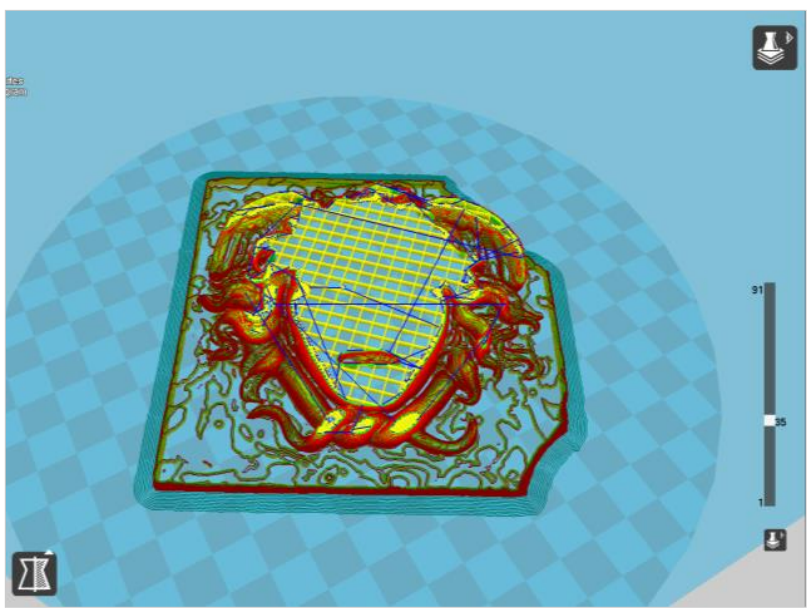

Figure 10. The main screen of Cura; the Medusa mask, horizontal position, layers view model

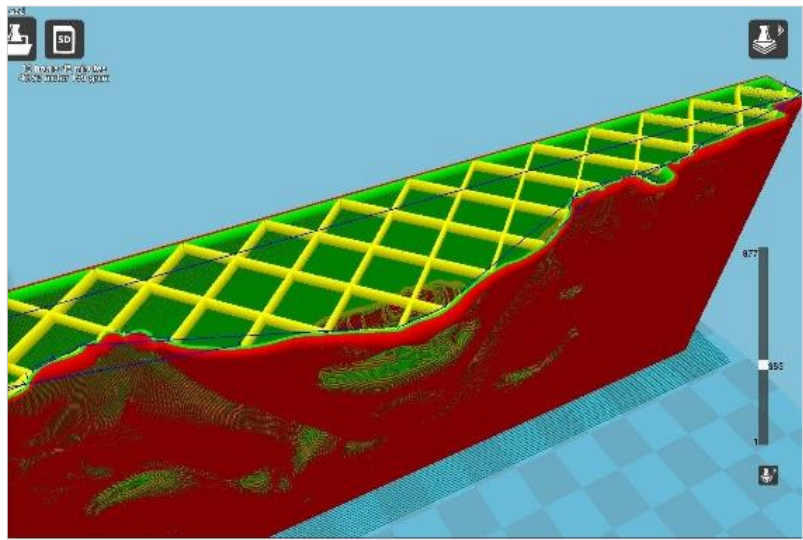

Figure 11. The main screen of Cura; the Medusa mask, vertical position, layers view mode. Detail of its fill density 

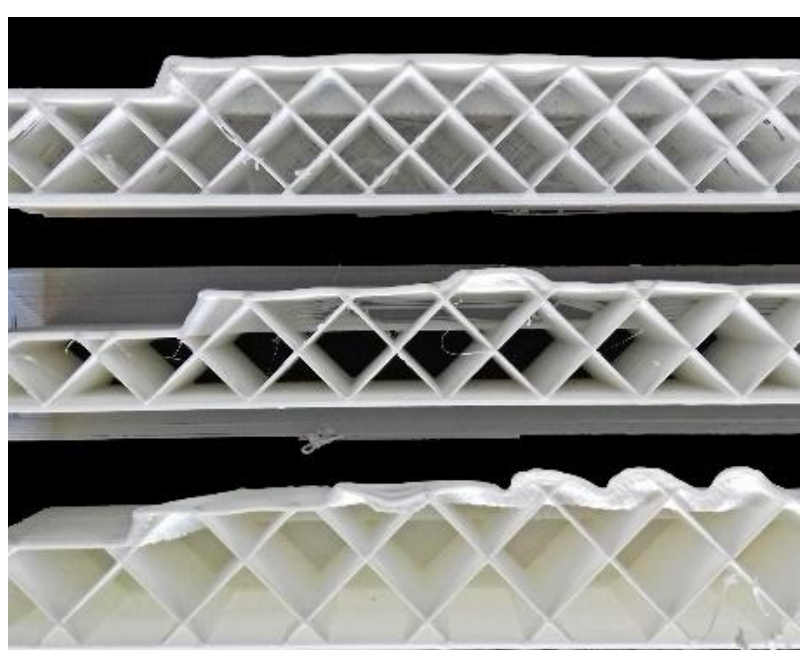

Figure 12. Three prototypes of the Medusa mask, vertical position. Different settings of fill density (10-15-20\%).

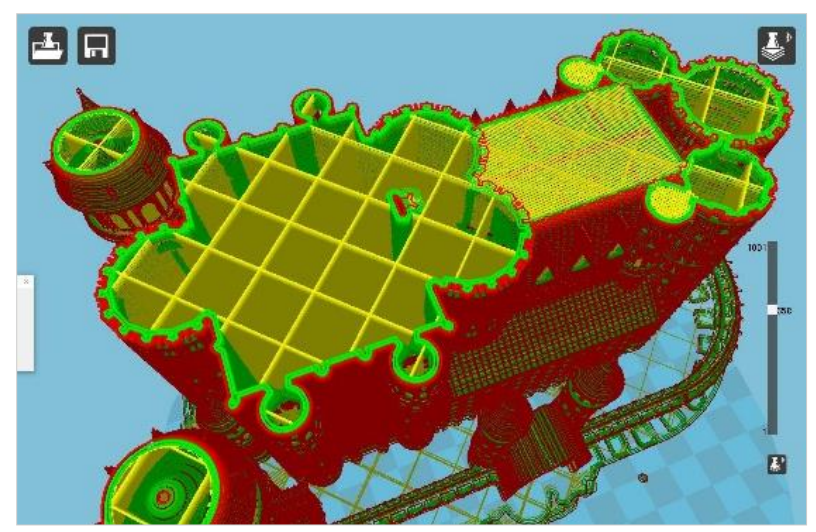

Figure 13. The main screen of Cura;

medieval castle model, detail of its bottom/top thickness

The filament is extruded at temperatures varying in relation to the type used $\left(200-250{ }^{\circ} \mathrm{C}\right)$; a temperature setting that's either too high or too low can lead to problems (Fig. 14, 15, 16, 17, 18).

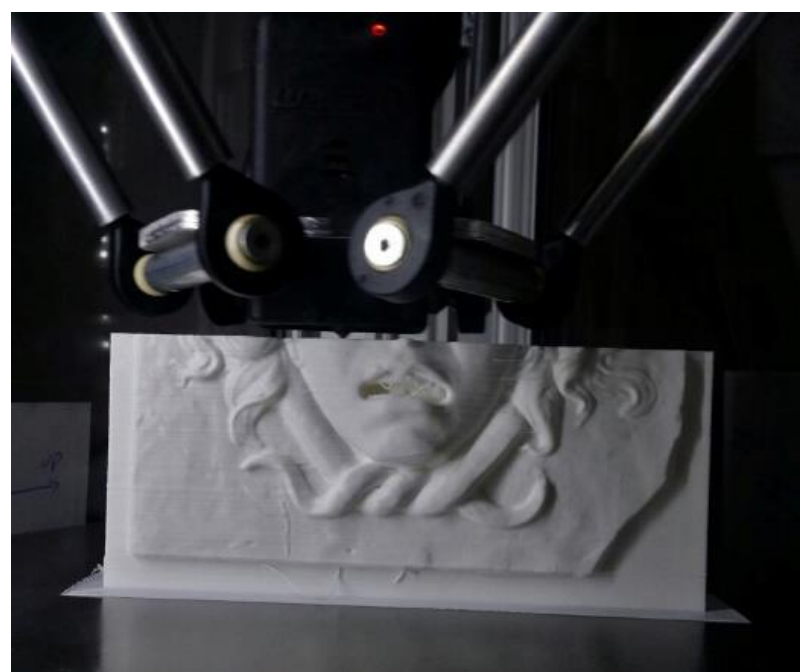

Figure 14. During 3D print of the Medusa mask

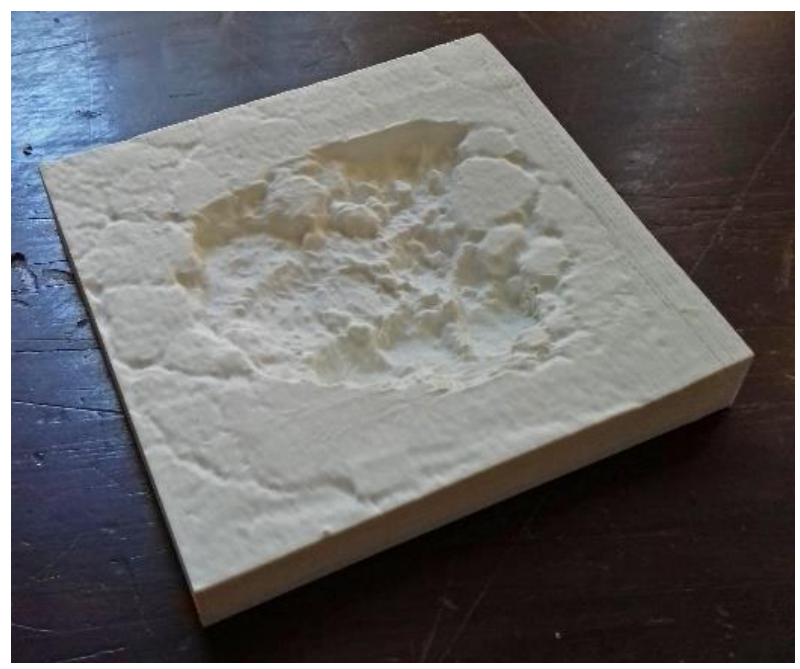

Figure 15.3D print of the pothole model.

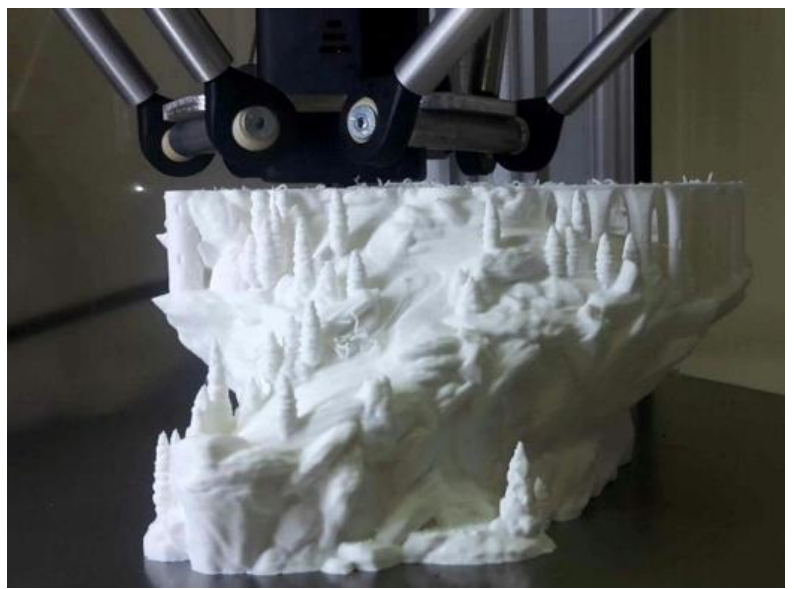

Figure 16. During 3D print of the medieval castle model

The speed and temperature used for printing have a big influence on how the plastic comes out of the nozzle. When the temperature is too low, the material won't melt properly as cooler plastic is more viscous and requires higher pressures to push it through the nozzle. The pressures will become too high and under-extrusion happens.

Keep in mind that lowering the printing temperature means that we, probably, need to decrease the print speed as well to ensure the plastic will completely melt before it leaves the nozzle.

On the other hand, when the temperature's too high, it can cause problems as the properties of the material will start to change if left in the nozzle for too long, causing clogs.

Furthermore, it's very important that the first layer is nicely pressed onto the plate with flat lines of filament and no gaps in between.

When our model does not have a completely flat bottom or if we want to improve the bed adhesion we can use one of the platform adhesion types: raft or brim.

A raft adds a thick grid between the model and the build plate. Instead, a brim is an extension of the first print layer, some extra lines of plastic are placed around the object on the first layer of the print. Being broader, it improves the general adhesion to the plan. Especially brim is used a lot and works very well if we want to decrease the amount of warping on your print. 


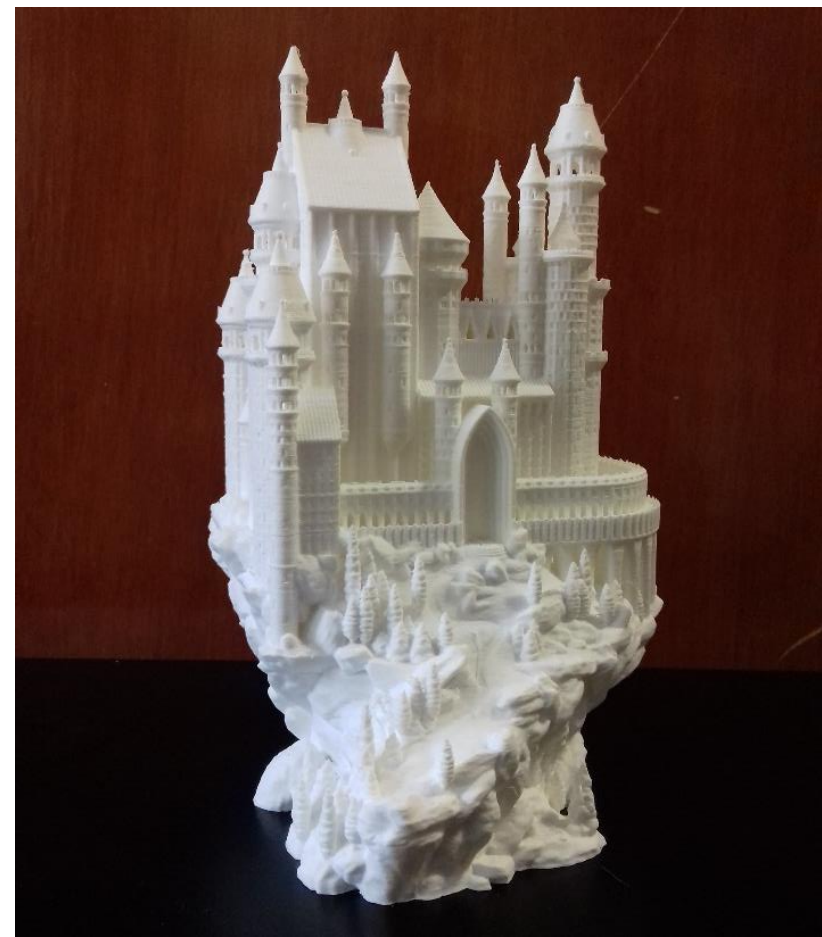

Figure 17. 3D print of medieval castle model
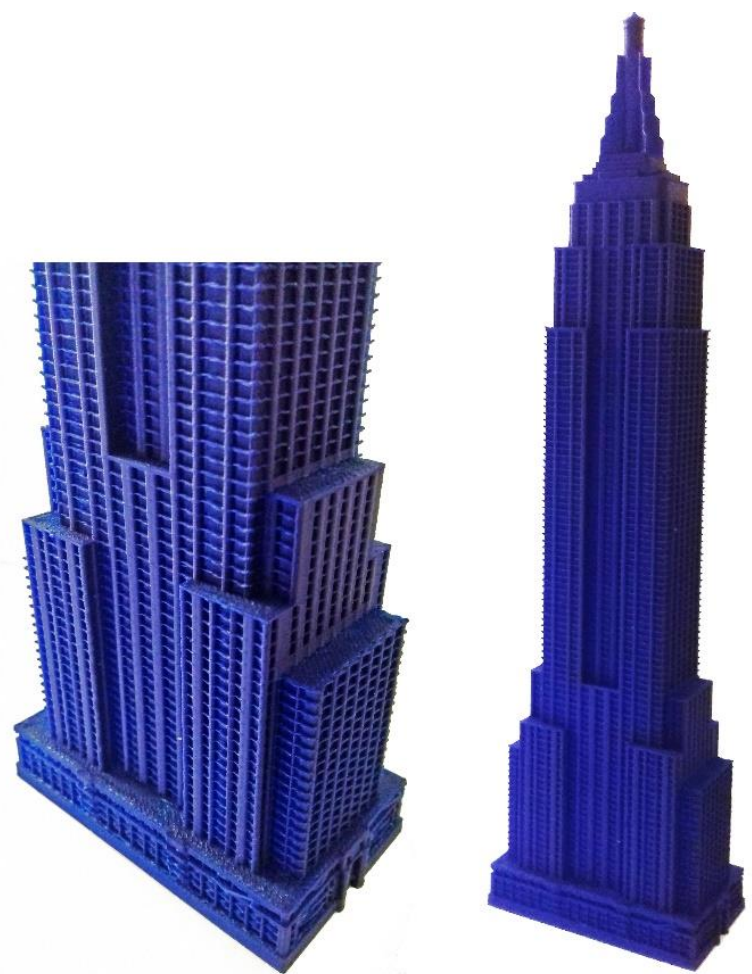

Figure 18. 3D print of the Empire State Building model

The process prints layer by layer, for a total time variable in relation to the complexity of the object shape.

The chamber is then progressively cooled to ambient temperature. The final operation consists in the mechanical removal of the support material.

\section{RESULTS AND DISCUSSION}

Conducted experimentation has required many attempts for each model, before reaching an optimal level of accuracy of the 3D printing. We have encountered many difficulties in searching for standard parameterization.

Tab 19 shows that the position of the model in the Cura space (horizontal or vertical position) can significantly change the result of the final 3Dprint reducing the aliasing effects.

\begin{tabular}{|c|c|c|c|c|c|}
\hline \multirow[b]{2}{*}{$\begin{array}{c}\text { Machine } \\
\text { Settings_- } \\
\text { Basic/Adva } \\
\text { nced } \\
\text { parameters }\end{array}$} & \multicolumn{5}{|c|}{ Objects } \\
\hline & 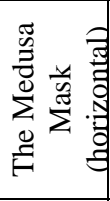 & 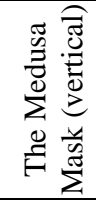 & $\begin{array}{l}\frac{0}{\circ} \\
\text { Ẽ } \\
0\end{array}$ & 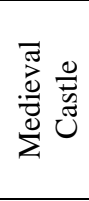 & 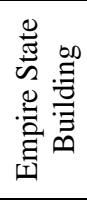 \\
\hline $\begin{array}{c}\text { Layer } \\
\text { height }(\mathrm{mm})\end{array}$ & 0,2 & 0,2 & 0,2 & 0,2 & 0,15 \\
\hline $\begin{array}{c}\text { Shell } \\
\text { thickness } \\
(\mathrm{mm})\end{array}$ & 0,8 & 0,8 & 0,8 & 1,2 & 1,2 \\
\hline $\begin{array}{l}\text { Top/bottom } \\
\text { thickness } \\
(\mathrm{mm})\end{array}$ & 1 & 0,8 & 0,8 & 0,8 & 1 \\
\hline $\begin{array}{c}\text { Fill Density } \\
(\%)\end{array}$ & 20 & 10 & 10 & 10 & 5 \\
\hline $\begin{array}{c}\text { Printing } \\
\text { temperature } \\
\left({ }^{\circ} \mathrm{C}\right)\end{array}$ & 175 & 200 & 200 & 210 & 200 \\
\hline $\begin{array}{l}\text { Build Plate } \\
\text { temperature } \\
\left({ }^{\circ} \mathrm{C}\right)\end{array}$ & 60 & 40 & 40 & 40 & 40 \\
\hline $\begin{array}{l}\text { Nozzle } \\
\text { diameter } \\
(\mathrm{mm})\end{array}$ & 1,75 & 1,75 & 1,75 & 1,75 & 1,75 \\
\hline Flow $(\%)$ & 100 & 105 & 105 & 120 & 110 \\
\hline $\begin{array}{l}\text { Enable } \\
\text { retraction }\end{array}$ & active & active & active & active & active \\
\hline $\begin{array}{l}\text { Print speed } \\
(\mathrm{mm} / \mathrm{s})\end{array}$ & 70 & 70 & 70 & 80 & 80 \\
\hline $\begin{array}{l}\text { Travel } \\
\text { speed } \\
(\mathrm{mm} / \mathrm{s})\end{array}$ & 70 & 70 & 70 & 120 & 120 \\
\hline $\begin{array}{c}\text { Print } \\
\text { process time }\end{array}$ & $\begin{array}{c}3 \mathrm{~h} \\
39 \mathrm{~m}\end{array}$ & $\begin{array}{l}10 \mathrm{~h} \\
45 \mathrm{~m}\end{array}$ & $\begin{array}{c}4 \mathrm{~h} \\
39 \mathrm{~m}\end{array}$ & $\begin{array}{l}25 \mathrm{~h} \\
40 \mathrm{~m}\end{array}$ & $\begin{array}{l}14 \mathrm{~h} \\
25 \mathrm{~m}\end{array}$ \\
\hline
\end{tabular}

Table 19. Machine settings, Basic/Advanced parameters. Comparison of the values assigned to case studies

In general, the choice of the printer type, the model, the type of material used, the editing algorithms and file processing, the shape of the object to be reproduced and the parameter settings significantly influence the results and impose limits and choices at times, forced.

In addition, the parameters that regulate speed, temperature, resolution, and fill percentage determine, more than any other parameter, the $3 \mathrm{D}$ print times and are directly related to $3 \mathrm{D}$ print 
accuracy. A proper balance between temperature and speed can avoid incurring frequent errors such as: the corners deformation (warping) due to shrinkage of the material; the sub-extrusion phenomena, perforated surfaces, etc.

It is very important to control the printing of the first layer. You must check the quality and adhesion of the first layer of melted material on the printing plate. Any errors, could be due to: nozzle distance from the plate; dish level; extruder and plate temperatures. It is possible to intervene on these values on the device display directly ( $\mathrm{Lu}$, et al. 2014).

\section{CONCLUSIONS}

In this paper, we demonstrated that there is a workflow that the practitioner can use to have a friendly approach with its first printing. Nevertheless, it is necessary to have a considerable confidence with own printer to have the best result.

The automation of the 3D printing is going to be realized, but it will be necessary that this necessity will become a necessity of the building printer industry. It depend on the commercial development of the international financial market.

It is predicted by some additive manufacturing advocates that this technological development will change the nature of commerce, because end users will be able to do much of their own manufacturing rather than engaging in trade to buy products from other people and corporations (Bird, 2012).

$3 \mathrm{D}$ printers capable of outputting in colour and multiple materials already exist and will continue to improve to a point where functional products will be able to be output. With effects on energy use, waste reduction, customization, product availability, medicine, art, construction and sciences, 3D printing will change the manufacturing world as we know it.

\section{REFERENCES}

Alberghina, M., Alberghina, F., Allegra, D., Di Paola, F., Maniscalco, L., Milazzo, G., et al., 2016. Integrated threedimensional models for noninvasive monitoring and valorization of the Morgantina silver treasure (Sicily). In Journal of Electronic Imaging (JEI), 26 (1), 1-14.

Arbace, L. et al., 2012. Innovative uses of 3D digital technologies to assist the restoration of a fragmented terracotta statue, Journal of Cultural Heritage, vol. 14 (4)

http://dx.doi.org/10.1016/j.culher.2012.06.008.

Bird, J., 2012. Exploring the 3D printing opportunity. In The Financial Times. Retrieved 2012-08-30.

Excell, J., 2013. The rise of additive manufacturing. In The Engineer, Retrieved 2013-10-30.

Fantini, M., De Crescenzio, F., Persiani, F., Benazzi, S. Gruppioni, G., 2008. 3D restitution, restoration and prototyping of a medieval damaged skull. In Rapid Prototyping Journal 14, pp. 318-324.

Freedman, D.H., 2012. Layer By Layer. In Technology Review, 115 (1): 50-53.

Gibson, I., Rosen, D., Stucker, B., 2014. 3D Printing, Rapid Prototyping, and Direct Digital Manufacturing, Springer, ISBN: 978-1-4939-2112-6 (Print) 978-1-4939-2113-3.
Inzerillo, L., Dalli Cardillo, G. (2013) Architectural Library. The Dioscuri Temple in Agrigento. In 21st International Conference in Central Europe on Computer Graphics, Visualization and Computer Vision, WSCG 2013, pp. 33-36

Inzerillo, L., Santagati, C., Di Paola, F., 2013. Image-based modeling techniques for architectural heritage 3D digitalization: limits and potentialities, in International Archives of the Photogrammetry, Remote Sensing and Spatial Information Sciences, XL-5(W2): pp. 550-560.

Kodama, H., 1981a. A Scheme for Three-Dimensional Display by Automatic Fabrication of Three-Dimensional Model. In IEICE Transactions on Electronics, Japanese Edition, vol. J64C, No. 4, pp. 237-41.

Kodama, H., 1981b. Automatic method for fabricating a threedimensional plastic model with photo-hardening polymer. Review of Scientific Instruments, Vol. 52, No. 11, pp. 1770-73.

Lo Presti, S., Di Paola, F., Mineo, S., 2011. Artificial stone in architecture: new techniques of intervention in the Utveggio Castle in Palermo, in Conservation Science in Cultural Heritage, Issue n. 11, pp. 195-217, DOI: 10.6092/ISSN.1973-9494/2698.

Lu, L., Sharf, A., Zhao, H., Wei, Y., Fan, Q., Chen, X., Savoye, Y., Tu, C., Cohen-Or, D. and Chen, B., 2014. Build-to-last: Strength to weight 3D printed objects. In ACM Transactions on Graphics (Proc. SIGGRAPH), 33, 4, August, 97:1- 97:10.

Mendoza, H.R., 2015. Alain Le Méhauté, The Man Who Submitted Patent for SLA 3D Printing Before Chuck Hull. https://3dprint.com/

Menna, F., Nocerino, E., Remondino, F., Dellepiane, M., Callieri, R., Scopigno, R., 2016. 3D digitization of an heritage masterpiece - A critical analysis on quality assessment. in International Archives of the Photogrammetry, Remote Sensing and Spatial Information Sciences, Volume XLI-B5, 2016, XXIII ISPRS Congress, (12-19 July 2016), Prague, Czech Republic.

Neumüeller, M., Reichinger, A., Rist, F., Kern, C., 2014. 3D printing for cultural heritage: Preservation, accessibility, research and education. In $3 D$ Research Challenges in Cultural Heritage, Ioannides M., Quak E., (Eds.), vol. 8355 of Lecture Notes in Computer Science. Springer Berlin Heidelberg, 2014, pp. 119134.

Taufik, M., Jain, P.K., 2014. Role of build orientation in layered manufacturing: a review. International Journal of Manufacturing Technology and Management. 27 (1/2/3): 47-73. DOI:10.1504/IJMTM.2013.058637. 